\title{
Cannabinoid Therapeutics in Chronic Neuropathic Pain: From Animal Research to Human Treatment
}

\author{
Raquel Maria P. Campos*, Andrey F. L. Aguiar, Yolanda Paes-Colli, \\ Priscila Martins Pinheiro Trindade, Bruna K. Ferreira, Ricardo A. de Melo Reis and \\ Luzia S. Sampaio*
}

Laboratório de Neuroquímica, Instituto de Biofísica Carlos Chagas Filho (IBCCF), Centro de Ciências da Saúde, Universidade Federal do Rio de Janeiro, Rio de Janeiro, Brazil

OPEN ACCESS

Edited by:

Emer S. Ferro

University of São Paulo, Brazil

Reviewed by:

Patrícia Reckziegel,

Universidade Federal de São Paulo,

Brazil

Chi Him Eddie Ma

City University of Hong Kong,

Hong Kong SAR, China

Alexandra Latini,

Federal University of Santa Catarina

Brazil

*Correspondence:

Luzia S. Sampaio sampaio.lu@biof.ufri.br

Raquel Maria P. Campos

camposrp@biof.ufrj.br

Specialty section:

This article was submitted to Integrative Physiology,

a section of the journal

Frontiers in Physiology

Received: 28 September 2021 Accepted: 10 November 2021 Published: 30 November 2021

Citation:

Campos RMP, Aguiar AFL,

Paes-Colli Y, Trindade PMP, Ferreira BK, de Melo Reis RA and

Sampaio LS (2021) Cannabinoid Therapeutics in Chronic Neuropathic

Pain: From Animal Research

to Human Treatment.

Front. Physiol. 12:785176.

doi: 10.3389/fphys.2021.785176
Despite the importance of pain as a warning physiological system, chronic neuropathic pain is frequently caused by damage in the nervous system, followed by persistence over a long period, even in the absence of dangerous stimuli or after healing of injuries. Chronic neuropathic pain affects hundreds of millions of adults worldwide, creating a direct impact on quality of life. This pathology has been extensively characterized concerning its cellular and molecular mechanisms, and the endocannabinoid system (eCS) is widely recognized as pivotal in the development of chronic neuropathic pain. Scientific evidence has supported that phyto-, synthetic and endocannabinoids are efficient for pain management, while strong data arise from the therapeutic use of Cannabis-derived products. The use of medicinal Cannabis products is directed toward not only relieving symptoms of chronic pain, but also improving several aspects of patients' welfare. Here, we review the involvement of eCS, along with other cellular and molecular elements, in chronic neuropathic pain pathology and how this system can be targeted for pain management.

Keywords: neuropathic pain, endocannabinoid, cannabidiol, THC, cannabis

\section{CHRONIC NEUROPATHIC PAIN}

Chronic pain is classified by the International Association for the Study of Pain (IASP) as a pain that lasts more than 3 months, even after its primary cause is cured (Raja et al., 2020). One of the main types of chronic ache is neuropathic pain, that occurs when pain is caused by a lesion or disease of the somatosensory nervous system (Raja et al., 2020). Chronic neuropathic pain

Abbreviations: 2-AG, 2-arachidonoylglycerol; AEA, anandamide; ASR-9, aggregated 9-factor symptom relief; ATP, adenosine triphosphate; cAMP, cyclic adenosine monophosphate; CB1R, cannabinoid receptor type 1; CB2R, cannabinoid receptor type 2; $\mathrm{CBC}$, cannabichromene; $\mathrm{CBD}$, cannabidiol; $\mathrm{CBDV}$, cannabidivarin; $\mathrm{CBN}$, cannabinol; $\mathrm{CNS}$, central nervous system; COX-2, cyclooxygenase-2; CYP, cytochrome p450; DRG, dorsal root ganglia; EAAT2, excitatory amino acid transporter 2; eCBs, endocannabinoids; eCS, endocannabinoid system; eEPSC, evoked excitatory postsynaptic currents; FAAH, fatty acid amino hydrolase; GABA, $\gamma$-aminobutyric acid; IASP, International Association for the Study of Pain; IL-17, interleukin 17; IL-1 $\beta$, interleukin 1 $\beta$; IL-6, interleukin 6; MAGL, monoacylglycerol lipase; NF-кb, nuclear factor $\kappa$ B; P2X4 - P2X purinoceptor 4; p38 MAPK, p38 mitogen-activated protein kinase; PDQ7, Pain Detect Questionnaire 7; PEA, palmitoylethanolamide; PNS, peripheral nervous system; THCV, $\Delta^{9}$-tetrahydrocannabivarin; TNF- $\alpha$, tumor necrosis factor- $\alpha$; TRP, transient receptor potential; TRPA1, transient receptor potential subfamily A member 1; TRPM8, transient receptor potential subfamily $\mathrm{M}$ member 8 ; TRPV1, transient receptor potential subfamily V member $1 ; \Delta^{9}-\mathrm{THC}, \Delta^{9}$ tetrahydrocannabinol. 
has several causes, such as the use of medicines (chemotherapy drugs, for example), metabolic diseases (such as diabetic neuropathy), demyelinating diseases (for instance, multiple sclerosis) and mechanical injuries (Meacham et al., 2017; Alles and Smith, 2018). The epidemiology of this disease varies across the globe, but it is estimated that $7-10 \%$ of all adults worldwide suffer from chronic neuropathic pain (van Hecke et al., 2014; Mücke et al., 2018). The main symptoms consist of spontaneous burning pain, numbness, and hyperalgesia (increased pain perception of noxious stimuli) and allodynia (pain hypersensitivity to normally innocuous stimuli) (Rani Sagar et al., 2012; Meacham et al., 2017; Alles and Smith, 2018). Patients may also experience social and economic consequences, since it is highly uncomfortable to conduct routine tasks while feeling pain. The physical and social impairment, along with the daily pain, can occasionally lead to depression (Knaster et al., 2012; Radat et al., 2013; Pitcher et al., 2019).

Physiological pain pathways include the peripheral and central nervous system (PNS and CNS, respectively), and the pain matrix revealed by neuroimaging in the last two decades is formed by central areas responsible for the process of pain (Legrain et al., 2011; Figure 1). Here, we focus on the plasticity in the spinal cord, particularly in the dorsal horn, due to its key role as a central integrator of afferent sensory information, besides being a region where significant part of pain processing occurs (Rani Sagar et al., 2012; West et al., 2015; Alles and Smith, 2018).

\section{ANATOMICAL, CELLULAR, AND MOLECULAR ELEMENTS OF PAIN PROCESSING IN THE SPINAL CORD}

The spinal cord is protected by the vertebral column and it is involved in motor and sensory processing, in addition to integrating the body with the brain through different pathways. Anatomically, the spinal cord is divided into an external white matter and an internal gray matter. The latter is subdivided in 10 laminae going from dorsal to ventral spinal cord, which differ from each other based on inputs received and neuron types (Rexed, 1952).

The dorsal horn consists of laminae I to VI, and receives information mostly from sensory neurons located in the dorsal root ganglia (DRG). The DRG neurons transduce mechanical, thermal or nociceptive information and can be classified as $A \delta$, C, or A $\beta$ fibers (Rexed, 1952; Le Pichon and Chesler, 2014; Alles and Smith, 2018). Lamina I receives noxious, mechanical and thermal inputs from $\mathrm{A} \delta$ and $\mathrm{C}$ fibers. Lamina II consists of two zones: the outer zone, which receives inputs from $\mathrm{C}$ fibers, and the inner zone, receiving information from $\mathrm{A} \delta$ and $\mathrm{C}$ fibers. $\mathrm{A} \delta$ and $A \beta$ fibers connect with other neurons in Laminae III to $\mathrm{V}$ carrying tactile and pressure information. Lamina VI receives sensory information from muscle spindles, consisting mostly of propriospinal neurons (Figure 1). All laminae have a high number of inhibitory GABAergic and glycinergic interneurons that help modulate sensory inputs. Also, it is important to highlight that most of the laminae in the dorsal horn make connections with neurons from different brain regions through ascendant and descendant pathways (West et al., 2015; Alles and Smith, 2018; Figure 1).

The synapses between $\mathrm{A} \delta, \mathrm{A} \beta$, and $\mathrm{C}$ fibers and spinal cord neurons are excitatory, having glutamate as neurotransmitter (West et al., 2015; Alles and Smith, 2018). Glutamate release from sensory fibres is regulated by inhibitory interneurons present in all laminae of the dorsal horn through $\gamma$-aminobutyric acid (GABA) or glycine release, modulating noxious transmission (West et al., 2015). The sensory information travels through different pathways, such as the spinothalamic tract, to different brain areas known as pain matrix, which includes the thalamus, the anterior cingulate cortex, the periaqueductal gray matter, the amygdala and others (D'Mello and Dickenson, 2008; Cohen and Mao, 2014; Colloca et al., 2017; Figure 1). Pain modulation is a top-down process: after information processing in higher brain centers, neurons that form the descendant pathways make synapses in the dorsal horn, releasing serotonin, GABA and glycine (D'Mello and Dickenson, 2008; Ossipov et al., 2010; West et al., 2015; Colloca et al., 2017; Figure 1).

\section{ENDOCANNABINOID SYSTEM IN PHYSIOLOGICAL PAIN PROCESSING}

The endocannabinoid system (eCS) main components are the G protein-coupled cannabinoid receptors $\mathrm{CB} 1$ (CB1R) and CB2 (CB2R), the endocannabinoids (eCBs) for example anandamide (AEA) and 2-arachidonoylglycerol (2-AG), and the enzymes involved in their metabolism, such as fatty acid amino hydrolase (FAAH) and monoacylglycerol lipase (MAGL), responsible for the degradation of AEA and 2-AG, respectively (Howlett et al., 2002; Figure 2). The eCS is an on-demand system and heterogeneously present in different structures of the CNS and PNS, including important regions of pain processing, such as the DRGs, spinal cord, thalamus, amygdala and others (Tsou et al., 1998; Farquhar-Smith et al., 2000; Katona et al., 2001; Starowicz and Finn, 2017; Finn et al., 2021; Figure 1).

In relation to pain modulation in the dorsal spinal cord, the eCS acts as a regulator of the synaptic transmission in the DRGs. CB1R is expressed in the presynaptic sensory fibers of trigeminal ganglion and dorsal root ganglion, besides the nerve endings of primary sensory neurons in dermis, whose afferent fibers conduct nociception (Salio et al., 2002; Price et al., 2003; Veress et al., 2013; Zou and Kumar, 2018). Following the release of neurotransmitters, glutamatergic receptors are activated in the postsynaptic terminal, inducing $\mathrm{Ca}^{2+}$ influx and its increased concentration inside the cell. Therefore, higher levels of intracellular $\mathrm{Ca}^{2+}$ promotes activation of enzymes responsible for eCBs synthesis, mostly AEA and 2$A G$, which are then released into the synaptic cleft and bind to CBRs in the presynaptic terminal. CBR activity induces blockade of voltage-gated $\mathrm{Ca}^{2+}$ channels presynaptically and inhibits adenylate cyclase, decreasing levels of cAMP and triggering the signaling cascade involved in synaptic plasticity, besides modulating sensory transmission through this feedback mechanism in the dorsal horn (Shen et al., 1996; Mecha et al., 2015; Figure 2A). This was demonstrated by the development 


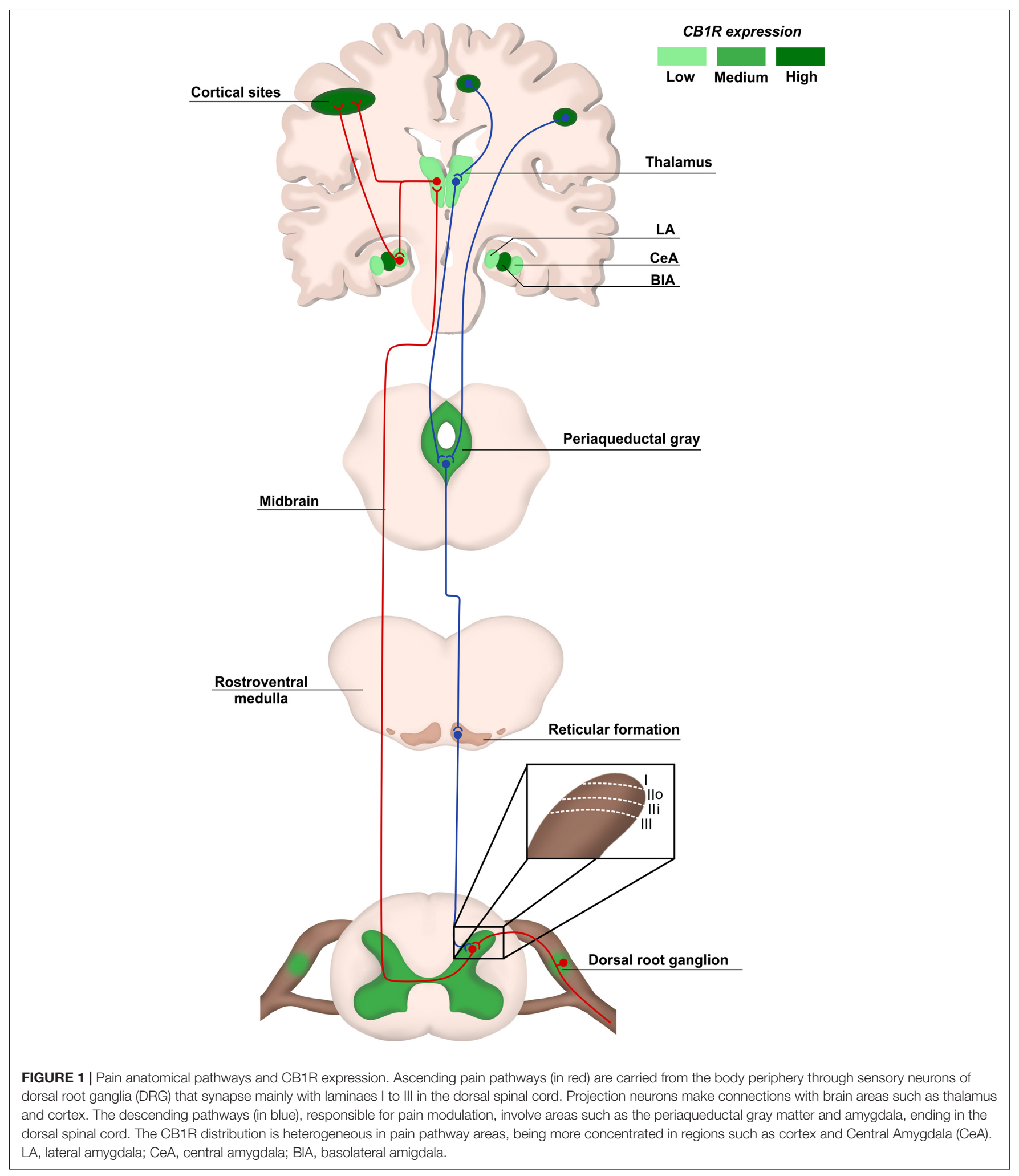

of thermal hyperalgesia and blockage of inhibition of evoked excitatory postsynaptic currents (eEPSC) in laminae II neurons in mice after administration of CB1R antagonists (Richardson et al., 1997; Yang et al., 2016).
Another important component associated with the eCS is the transient receptor potential family (TRP). The TRP cation channel subfamily V member 1 (TRPV1) has a relevant role in nociceptive transduction in the PNS since it is activated, opening 
a $\mathrm{Ca}^{2+}$ channel and increasing this ion concentration inside the neurons, by heat, acidic substances and capsaicin, besides being expressed in the soma and nerve terminals of sensory neurons from DRG (Caterina et al., 1999; Immke and Gavva, 2006; Lauria et al., 2006). The TRP cation channel subfamily $M$ member 8 (TRPM8) and subfamily A member 1 (TRPA1) also act as nociceptors and they are activated by menthol/cold temperatures and noxious cold/pungent compounds, respectively (Storozhuk and Zholos, 2018). Although TRPV1 and TRPM8 were not initially considered eCS-related receptors, they are directly influenced by different endocannabinoids, such as AEA, since this molecule is an agonist for the former and antagonist for the latter (Zygmunt et al., 1999; De Petrocellis et al., 2007; Figure 2A).

Clinical evidence for the role of the eCS in pain management was reported based on a serendipitous case of a Scottish patient (Habib et al., 2019). Authors described the clinical data from a woman submitted to orthopedic surgery, a procedure recognized for being associated with severe pain, with no need for analgesics. The same patient also had a long clinical history of cuts and burns without any sensation of pain. Genetic investigation revealed a deletion in the gene responsible for FAAH transcription, which led to reduced degradation and higher levels of AEA in peripheral blood and probably other organs.

The major eCS components are also present in glial cells, such as astrocytes and microglia, even though $\mathrm{CB} 2 \mathrm{R}$ is more expressed than CB1R in microglia, as also shown in other immunological cells, such as lymphocytes and neutrophils (Hegyi et al., 2009; Greineisen and Turner, 2010; Maccarrone et al., 2015). In astrocytes, CB1R-mediated signaling promotes increase of intracellular $\mathrm{Ca}^{2+}$ levels, while activation of microglial CB2R maintains the resting state or anti-inflammatory polarity of this cell type (Greineisen and Turner, 2010; Mecha et al., 2015; Figure 2A).

\section{CELLULAR AND MOLECULAR CHANGES IN THE SPINAL CORD ASSOCIATED WITH CHRONIC NEUROPATHIC PAIN}

The nervous system is plastic, with the ability to change and readapt in response to environmental stimuli. In this context, maladaptive plasticity processes can result in malfunction of the nervous system physiology (Kuner and Flor, 2017; Meacham et al., 2017). For instance, hyperalgesia is related to neuronal hyperexcitability triggered by cytokines and inflammatory mediators released in the periphery or in the spinal cord (Colloca et al., 2017; Kuner and Flor, 2017; Meacham et al., 2017). This is followed by a decrease of GABA- and glycine-mediated neurotransmission, caused not only by the reduction of their release, but also because of inhibitory interneurons apoptosis (Moore et al., 2002; Janssen et al., 2011; Foster et al., 2015). The decrease of GABA-mediated signaling reduces presynaptic inhibition, especially in Lamina II, which allows $A \beta$ fibers to communicate with neurons in Lamina I, therefore contributing for allodynia (Alles and Smith, 2018).
The central sensitization of the spinal cord, which is the increased responsiveness of nociceptive neurons in the CNS when compared to normal threshold, may occur for several reasons, one of them being the dysfunction of glutamate signaling (Meacham et al., 2017). The expression of glutamate transporters is downregulated after PNS injury, increasing the availability of glutamate to their receptors and decreasing neuron-firing threshold (Sung et al., 2003). Changes in the expression of voltage-gated calcium channels, such as the upregulation of $\alpha 2 \delta-1$ subunit, also contribute to neuron hyperexcitability by increasing $\mathrm{Ca}^{2+}$ permeability to the intracellular medium (Li et al., 2004; D’Arco et al., 2015).

The unbalanced synaptic communication in the dorsal horn of the spinal cord is one of the main causes for chronic neuropathic pain consolidation. However, synapses not only contain pre- and postsynaptic elements, but also the participation of glial cells, such as astrocytes and microglia, which have their physiological state shifted and contribute to this pathology, similarly to neurons. After PNS injury, it is well-known that astrocytes and microglial cells in the spinal cord show increased reactivity, identifiable by changes in their morphology and secreted molecules (Burgos et al., 2012; Alles and Smith, 2018). After an aversive stimulus, these cells produce proinflammatory mediators, such as interleukins $-17,-1 \beta,-6$ (IL17, IL-1 $\beta$, and IL-6), and Tumor Necrosis Factor- $\alpha$ (TNF- $\alpha$ ), which establish an inflammatory environment involved in the maintenance of chronic neuropathic pain (Wieseler-Frank et al., 2005; Stemkowski et al., 2017). Part of these molecules are chemoattractant for immune cells, which explains the infiltration of T cells (Choi et al., 2015; Sun et al., 2017). Indeed, several studies describe the correlation between lymphocyte invasion in the spinal cord and the development of chronic pain, also by the production and release of cytokines as IL-17 by this cell type (Kleinschnitz et al., 2006; Davoli-Ferreira et al., 2020).

Glial cells are also involved in hyperalgesia and allodynia generation. Astrocytes potentiate glutamatergic signaling by reducing the expression of excitatory amino acid transporter 2 (EAAT2) in these cells, which promotes increased glutamate concentration externally to the neuron (Cata et al., 2006). In addition, the contents of purinergic receptors are increased in the microglial cytoplasmic membrane. The continuous adenosine triphosphate (ATP) release from injured and stressed cells in the microenvironment induces constant stimulation of microglia reactivity, proliferation and pro-inflammatory polarity (Tsuda et al., 2013; Peng et al., 2016; Alles and Smith, 2018). In fact, $\mathrm{P} 2 \mathrm{X}$ purinoceptor 4 (P2X4) stimulation in the spinal cord of noninjured adult rats is sufficient to induce allodynia (Tsuda et al., 2003; Niu et al., 2017).

\section{ENDOCANNABINOID SYSTEM AS TARGET FOR CHRONIC NEUROPATHIC PAIN TREATMENT}

As previously mentioned, the unbalance of eCS physiological signaling can induce chronic neuropathic pain symptoms (Richardson et al., 1997; Yang et al., 2016). The eCS components 

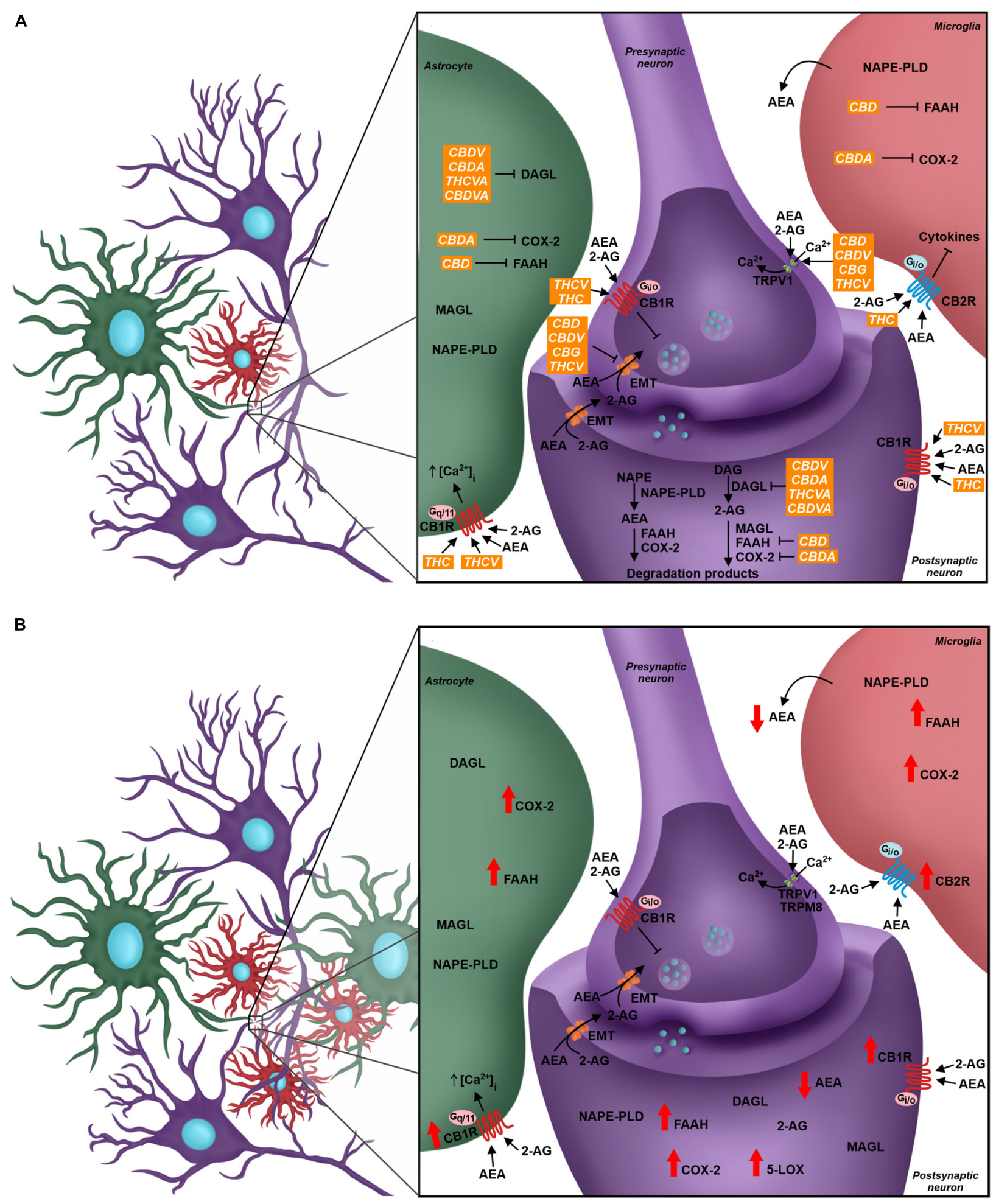

FIGURE 2 | The role of the endocannabinoid system (eCS) in the quadripartite synapse, its modulation by phytocannabinoids and alterations due to Neuropathic Pain. (A) Neurons, astrocytes, and microglial cells have the eCS components, and the endocannabinoid signaling through CB1R and CB2R leads to different outcomes in each cell. The presynaptic neuron expresses CB1R, TRPV1, TRPM8, and the endocannabinoid membrane transporter (EMT). Receptors are targeted by endocannabinoids (AEA and 2-AG). CB1R modulation activates signaling cascades that inhibit $\mathrm{Ca}^{2+}$ intracellular influx, which decreases the fusion of intracellular vesicles with the neuron membrane, changing the neurotransmitter release flow. The postsynaptic neuron also presents, besides the receptors, all the elements of the ECS, such as the AEA and 2-AG synthesis enzymes, respectively NAPE-PLD and DAGL, and the degradation enzymes, FAAH, MAGL, and other enzymes such 
FIGURE 2 | as COX2. In green: Astrocyte takes part in the synapse and expresses different elements of the eCS such as endocannabinoids' synthesis and degradation enzymes and cannabinoid receptors, where the activation of CB1R may favor the influx of $\mathrm{Ca}^{2+}$ ions. Microglia expresses components of the eCS; the CB2R expression is higher than CB1R, and its modulation is linked to the production and secretion of different cytokines. Phytocannabinoids modulate the eCS through many targets. THC and THCV are CB1R agonists, while CBD, CBDV, CBG, and THCV are TRPV1 agonists. The EMT transporter is the pharmacological target of the phytocannabinoids CBD, CBDV, CBG, and THCV. The phytocannabinoids also act over enzyme activity - CBD inhibits FAAH, CBDA inhibits COX-2 and CBDV, CBDA, THCVA and CBDVA inhibit DAGL. (B) In the Neuropathic Pain scenario, there is glial reactivity, leading to the increase of astrocyte and microglia next to neurons, especially in the dorsal spinal cord. The eCS is modulated and the levels of expression of your components change. There is a higher expression of CB1R and CB2R in neurons and glial cells. Enzymes such as FAAH, COX-2, and 5-LOX also increase their expression, and in result, there is a decrease of AEA levels and increase of pro-inflammatory mediators. CBD, cannabidiol; THC, tetrahydrocannabinol; CBDV; cannabidivarin; CBDA, cannabidiolic acid; THCVA, tetrahydrocannabivarinic acid; CBDVA, cannabidivarinic acid; THCV, tetrahydrocannabivarin; CBG, cannabigerol.

are highly susceptible to molecular alterations, and such events are observed in chronic neuropathic pain pathogenesis, both in the CNS and PNS (Rani Sagar et al., 2012; Starowicz and Finn, 2017). Indeed, it has been described that the expression of CB1R and $\mathrm{CB} 2 \mathrm{R}$, the eCB synthesis machinery and the expression of FAAH are increased in the spinal cord of animals submitted to murine models of chronic neuropathic pain (Zhang et al., 2003, 2010; Guindon et al., 2013; Davis, 2014; Malek et al., 2014). Although there is elevation in eCBs synthesis, activation of FAAH and alternative catabolic pathways, involving cytochrome 450 (CYP), cyclooxygenase-2 (COX-2) and lipoxygenases, increase AEA degradation and generates inflammatory mediators, such as prostaglandins, which influence neuron excitability (Kozak et al., 2002; Snider et al., 2009; Chouinard et al., 2011; Rani Sagar et al., 2012; Mecca et al., 2021). The reduction of AEA and CB1Rmediated negative feedback in excitatory synapses contribute to the hyperalgesia mechanism (Figure 2B).

The fact that the eCS is involved in the pathophysiological state of pain makes this system a valid target for chronic neuropathic pain treatment. Nowadays, treatments for chronic neuropathic pain consist of four lines of therapies that are chosen according to the patient's condition (Table 1), with opioids being the most used (Attal et al., 2010; Rani Sagar et al., 2012; Moulin et al., 2014; Finnerup et al., 2015).

Despite the variety of treatments, there are no effective pharmacotherapeutic strategies for mitigating chronic neuropathic pain, in addition to patients that do not respond properly to treatments and are resistant to current medicines available (Dworkin et al., 2010; Yekkirala et al., 2017). Moreover, there is a huge opioid crisis with severe consequences centered on drug addiction, respiratory depression and death by overdose (Moore and McQuay, 2005; Fornasari, 2017; CDC, 2021; WHO, 2021). The lack of a solid treatment with few or no side effects makes the pharmaceutical industry avid to pursue new alternatives for these patients, and the modulation of eCS has been considered a promising tool.

CB1R/CB2R agonists and antagonists have been described as a valuable option to successfully modulate the eCS in chronic neuropathic pain animal models, bringing an alternative of treatment for patients that do not respond well to other pharmacological therapies. In addition, an indicative that modulating cannabinoid receptors could be a good alternative instead of opioids is the increased density of cannabinoids receptors in the spinal cord, compared to opioid receptors (Hohmann et al., 1999), and high/moderate expression of cannabinoid receptors in brain areas responsible for pain modulation, such as cortex, amygdala and periaqueductal gray matter, at least in rodents (Befort, 2015; Figure 1).

In animal models of chronic neuropathic pain, the administration of the synthetic cannabinoid CP 55,940, a CB1R agonist, terminated thermal hyperalgesia and decreased mechanical allodynia, evaluated by hot plate test and von Frey test, respectively (De Vry et al., 2004; Scott et al., 2004; RomeroSandoval and Eisenach, 2007). A single administration of WIN55, 212-2, a mixed CB1R/CB2R-receptor agonist, 7 days after nerve ligation (a murine model of chronic neuropathic pain), reduced cold allodynia and thermal hyperalgesia symptoms, evaluated by acetone and hot plate test, respectively (Bridges et al., 2001; Rahn et al., 2007). The use of WIN55, 212-2 also improved mechanical allodynia at von Frey test in chemotherapy-induced chronic neuropathic pain, when animals presented behavior similar to those treated with opioids (Rahn et al., 2007; Burgos et al., 2012). At the cellular level, this agonist reduced glial reactivity and expression of inflammatory mediators, such as IL-6 and TNF- $\alpha$ (Burgos et al., 2012). It is important to notice that the combination of WIN55, 212-2 with selective CB1R and CB2R antagonists, SR141716 and SR144528, respectively, reversed the allodynia improvement, evaluated by von Frey test, demonstrating that both cannabinoid receptors are directly involved in these mechanisms and can be targeted for treatment purposes (Rahn et al., 2007). In addition, injection of JWH133 or JWH015, CB2R agonists, decreases mechanical allodynia after partial nerve ligation (Romero-Sandoval and Eisenach, 2007; Romero-Sandoval et al., 2008; Yamamoto et al., 2008). As described, CB2R is mostly expressed by microglial cells, which have their migration, proliferation and polarity modulated by cannabinoid receptor activation (Hegyi et al., 2009; Stella, 2009; Greineisen and Turner, 2010). Alternatively, CB2R activation by AM1241 decreases the expression of purinergic receptors $\mathrm{P} 2 \mathrm{Y}$, which is upregulated in microglia of chronic neuropathic animals, and decreases nuclear factor $\kappa \mathrm{B}(\mathrm{NF}-\kappa \mathrm{B})$ and p38 mitogen-activated protein kinase (p38 MAPK) phosphorylation, both involved in microglial activation and inflammatory response (Niu et al., 2017). The addition of 2-AG and AEA in primary microglial cell cultures increased the expression of both cannabinoid receptors and arginase-1, a marker for M2 microglia polarity, which is associated with pro-healing and anti-inflammatory responses (Mecha et al., 2015). The direct administration of AEA also led to better sensorial behavior in neuropathic murine animals, increasing mechanical and thermal threshold, evaluated by von Frey and hot plate tests (Guindon and Beaulieu, 2006; Desroches et al., 2008). 
TABLE 1 | The four lines of treatment for chronic neuropathic pain.

\begin{tabular}{|c|c|c|c|}
\hline Treatment & Mechanism of action & Line of treatment & References \\
\hline Gabapentinoids & $\begin{array}{l}\alpha 2 \delta 2-1 \text { subunit of voltage-gated } \mathrm{Ca}^{2+} \text { channels } \\
\text { ligant }\end{array}$ & First-line treatment & $\begin{array}{l}\text { Attal et al., 2010; Moulin et al., 2014; Hennemann-Krause and } \\
\text { Sredni, 2016; Colloca et al., } 2017\end{array}$ \\
\hline $\begin{array}{l}\text { Tricyclic } \\
\text { antidepressants }\end{array}$ & $\begin{array}{l}\text { Inhibitors of Noradrenaline/Serotonin uptake } \\
\text { systems }\end{array}$ & First-line treatment & $\begin{array}{l}\text { Attal et al., 2010; Moulin et al., 2014; Hennemann-Krause and } \\
\text { Sredni, 2016; Colloca et al., } 2017\end{array}$ \\
\hline $\begin{array}{l}\text { Noradrenaline/serotonin } \\
\text { reuptake inhibitors }\end{array}$ & $\begin{array}{l}\text { Inhibitors of noradrenaline/serotonin reuptake } \\
\text { systems }\end{array}$ & First-line treatment & $\begin{array}{l}\text { Attal et al., 2010; Moulin et al., 2014; Hennemann-Krause and } \\
\text { Sredni, 2016; Colloca et al., } 2017\end{array}$ \\
\hline Weak opioids & Opioid receptors agonists & Second-line treatment & $\begin{array}{l}\text { Attal et al., 2010; Moulin et al., 2014; Hennemann-Krause and } \\
\text { Sredni, 2016; Colloca et al., } 2017\end{array}$ \\
\hline Strong opioids & Opioid receptors agonists & Second-line treatment & $\begin{array}{l}\text { Attal et al., 2010; Moulin et al., 2014; Hennemann-Krause and } \\
\text { Sredni, 2016; Colloca et al., } 2017\end{array}$ \\
\hline Cannabinoids & Endocannabinoid system modulators & Third-line treatment & Attal et al., 2010; Moulin et al., 2014; Colloca et al., 2017 \\
\hline $\begin{array}{l}\text { Selective serotonin } \\
\text { reuptake inhibitors } \\
\text { (SSRI) }\end{array}$ & Inhibitors of selective serotonin reuptake system & Fourth-line treatment & Moulin et al., 2014 \\
\hline Botulinum toxin & Inhibitors of acetylcholine release & Fourth-line treatment & Moulin et al., 2014 \\
\hline Methadone & Opioid and NMDA receptors & Fourth-line treatment & Moulin et al., 2014 \\
\hline Lamotrigine & $\begin{array}{l}\text { Inhibitors of voltage-gated } \mathrm{Na}^{+} \text {and } \mathrm{Ca}^{2+} \\
\text { channels }\end{array}$ & Fourth-line treatment & Moulin et al., 2014 \\
\hline Lacosamide & $\begin{array}{l}\text { Slow inactivation of voltage-gated } \mathrm{Na}^{+} \\
\text {channels }\end{array}$ & Fourth-line treatment & Moulin et al., 2014 \\
\hline Tapentadol & $\begin{array}{l}\text { Opioid receptors agonist and inhibitor of } \\
\text { noradrenaline uptake system }\end{array}$ & Fourth-line treatment & Moulin et al., 2014 \\
\hline Topical lidocaine & Sodium channel blocker & Fourth-line treatment & Moulin et al., 2014 \\
\hline Topical capsaicin & TRPV1 receptor desensitization & Fourth-line treatment & Moulin et al., 2014 \\
\hline
\end{tabular}

Moreover, some studies referred to the catabolic enzyme FAAH as an alternative target to modulate eCB levels. Intraperitoneal administration of the FAAH blocker URB597 and MAGL blocker JZL184 led to an increase in the mechanical threshold and a reduction of cold allodynia, in von Frey and acetone tests, in chronic neuropathic rats, respectively (Clapper et al., 2010; Guindon et al., 2013). The oral administration of another FAAH blocker, ST4070, also produced the same improvement in several animal models of chronic neuropathic pain, such as those induced by chemotherapy drugs and diabetes (Caprioli et al., 2012). Changes in animal behavior due to pain is probably correlated to the increased availability of $\mathrm{eCB}$ and other bioactive lipids, for instance AEA and palmitoylethanolamide (PEA), respectively (Caprioli et al., 2012).

After the enlightenment of eCS participation in pain modulation in physiological and pathological states, researchers started to investigate if classical analgesics mechanisms could involve the eCS. Regarding the effects of dipyrone, a common non-steroidal anti-inflammatory drug widely used primarily as an analgesic and antipyretic, the exact action mechanisms remain controversial. Studies on mice suggest that dipyrone-induced suppression of thermal antinociceptive, hypothermic and locomotor activity is mediated by a CB1R/CB2R-independent mechanism (Schlosburg et al., 2012). On the other hand, AM251, a CB1 antagonist, reversed the effects of dipyrone on locomotor activity, cataleptic response and thermal analgesia (Crunfli et al., 2015). Both AM251 and capsazepine, a TRPV1 antagonist, favored the decrease in body temperature caused by dipyrone. However, the CB2 receptor antagonist AM630 did not alter the hypothermic response to dipyrone (Crunfli et al., 2015). These results suggest that the eCS role, especially CB1R-mediated, in the analgesic effect of dipyrone is still a matter of debate.

Although the evidence in animal models is promising and suggests that inhibitors of catabolic enzymes might be a way of treating chronic neuropathic pain, clinical trials did not show the same outcome. In January 2016, it came to public attention that a drug named BIA10-2474, a FAAH inhibitor, led to severe adverse events in some volunteers in the clinical trial, in which five people had to be hospitalized, two had brain damage and one died (Mallet et al., 2016). Nowadays, in clinical practice, the synthetic cannabinoids used to treat neuropathic chronic pain are Dronabinol (Marinol ${ }^{\circledR}$ - Solvay Pharmaceuticals) and Nabilone (Cesamet ${ }^{\circledR}$ - Meda Pharmaceuticals), both having a chemical formula based on $\Delta^{9}$-tetrahydrocannabinol $\left(\Delta^{9}\right.$ THC) (Stasiulewicz et al., 2020). Although these compounds may improve symptoms related to chronic neuropathic pain, some side effects such as euphoria, dysphoria, sleep disturbance and disorientation may occur. Diversely, the use of medicinal cannabis shows better results and less adverse events (CannabisIn-Cachexia-Study-Group et al., 2006; Frank et al., 2008; Narang et al., 2008; Aviram and Samuelly-Leichtag, 2017).

\section{MEDICINAL CANNABIS IN ANIMAL MODELS AND CLINICAL EVIDENCE}

Cannabis sp. has been used to treat several pathologies, including pain episodes, since ancient China (Bonini et al., 2018). The main components in Cannabis sp. are the phytocannabinoids, and more than 100 of these compounds have been described 
thus far. Even though the most investigated phytocannabinoids are cannabidiol (CBD) and $\Delta^{9}$-THC, the latter known for its psychoactive effect, several other phytocannabinoids such as cannabidivarin (CBDV), $\Delta^{9}$-tetrahydrocannabivarin (THCV) and their acidic forms are also being considered for therapeutic purposes (Di Marzo and Piscitelli, 2015; Cristino et al., 2020).

Phytocannabinoids act over several targets to modulate the eCS. For instance, while THC acts as CB1R and CB2R agonist, and THCV is a CB1R antagonist and TRPV1 agonist, CBD and CBDV inhibit eCB-degradation enzymes FAAH and MAGL (Di Marzo and Piscitelli, 2015; Cristino et al., 2020). Some phytocannabinoids also act in other neurochemical systems. For example, $\mathrm{CBD}$ can act over the serotoninergic and glycinergic receptors present in neurons, which are involved in pain processing, besides acting as TRPV1 and TRPM8 antagonist (Russo et al., 2005; De Petrocellis et al., 2008; Ahrens et al., 2009; García-Gutiérrez et al., 2020; Figure 2A).

Despite the recent statement from the IASP not encouraging the use of cannabinoids for pain treatment based on lack of quality researches reinforcing its safety and efficacy (IASP Presidential Task Force on Cannabis and Cannabinoid Analgesia, 2021), the positive outcomes and advantages over other pharmacological tools are compelling in animal research and clinical trials. For instance, Abraham et al. (2020) demonstrated in animals a phenomenon similar to what happens with patients. Neuropathic rats had a good response to morphine treatment, but the effect did not last up to 22 days after induction of pain, followed by drug-resistance. However, this effect was not observed in THC- and CBD-treated rats.

Tetrahydrocannabinol is known as the main analgesic compound from Cannabis sp. (Russo, 2008; Maayah et al., 2020). Several studies described a reduction of allodynic and hypersensitive behavior in animals, based on von Frey and hot plate tests results, after THC administration (Harris et al., 2016, 2019; Abraham et al., 2020). In addition to the fact that THC is a CB1R and CB2R agonist, reducing neurotransmitters release by neurons, especially glutamate, it also acts as TRPM8 antagonist and TRPA1 agonist (De Petrocellis et al., 2008; Storozhuk and Zholos, 2018). Another mechanism of action is inhibiting COX-2, which leads to increased levels of AEA and decreased levels of prostaglandins, whose therapeutic properties in chronic neuropathic pain pathology are the reduction of proinflammatory signaling, and probably, the decrease in glial and immunological cells response (Burstein et al., 1973; Ruhaak et al., 2011; Figure 2A).

CBD also contributes to decreased chronic neuropathic pain symptoms. Studies that investigated acute and chronic treatments of chronic neuropathic pain-induced rats with isolated CBD showed significantly increased mechanical and thermal threshold when compared to animals that received vehicle, evaluated by von Frey and hot plate tests (Xiong et al., 2012; Harris et al., 2016; King et al., 2017; Abraham et al., 2020; Silva-Cardoso et al., 2021). A plausible hypothesis that might explain how $\mathrm{CBD}$ improves the pathologic pain sensation is related to an increase in AEA levels due to FAAH inhibition and their agonist activity on TRPV1 agonist (Bisogno et al., 2001; Massi et al., 2008; Silva-Cardoso et al., 2021; Figure 2A). Silva-Cardoso et al.
(2021) also demonstrated that CBD treatment decreased CB1R expression in pain matrix regions, which was up-regulated in animals submitted to chronic neuropathic pain models.

Furthermore, the combination of CBD and THC synergizes their positive effects and reduces THC side effects (Carlini et al., 1974; McPartland and Russo, 2001). In fact, the coadministration of CBD and THC decreases dysphoria, anxiety, panic attacks, and other psychoactive effects that THC may cause (Grinspoon and Bakalar, 1993; King et al., 2017). Authors also described that CBD competes with THC for the binding site of CYP2C19 enzyme in the liver and inhibits THC hydroxylation, which prolongs THC bioavailability, and therefore its effects (Jones and Pertwee, 1972; Benowitz et al., 1980).

The involvement of other compounds from Cannabis sp. in pain improvement have also been reported, for example, cannabinol (CBN) and cannabichromene (CBC), acting as CB2R agonist and inhibitor of cyclooxygenase, respectively (Burstein et al., 1973; Showalter et al., 1996; Figure 2A). Terpenes are another class of secondary metabolites present in Cannabis sp. with biological relevance and they may play a role in pain treatment, such as the terpenoid $\beta$ caryophyllene, which directly modulates the eCS as a CB2R agonist (Gertsch et al., 2008). In the chronic neuropathic pain animal model, the daily gavage of $\beta$-caryophyllene decreased nociceptive hyperalgesia and mechanical allodynia in a dosedependent manner, as demonstrated by hot plate and von Frey tests. The treatment also reduced microglial reactivity and inflammatory response at spinal dorsal horn, probably due to $\beta$ caryophyllene-mediated increased expression of CB2R (Klauke et al., 2014; Segat et al., 2017). Other terpenoids participate in pain modulation through anti-inflammatory response. For instance, administration of $\beta$-myrcene increased thermal and nociceptive threshold either in healthy mice (Rao et al., 1990) or under inflammatory pain (Lorenzetti et al., 1991). Additionally, $\alpha$-pinene also seems to control pain through antiinflammatory pathways, decreasing cyclooxygenase-2 expression in an animal model of inflammatory pain (Li et al., 2016). Lastly, flavonoids, a group of chemical compounds present not only in Cannabis sp., but also in other plants, have antiinflammatory properties and can decrease the release of proinflammatory cytokines from astrocytes and microglia (Gui et al., 2018; Nadipelly et al., 2018).

Several compounds present in the Cannabis sp. extract synergize with each other and might modulate their effects when compared to isolated phytocannabinoids (Carlini et al., 1974; Russo, 2008). The synergistic action of phytocannabinoids producing a potentiated pharmacological effect is called entourage effect (King et al., 2017). This property was described in several studies that reported higher efficacy of Cannabis sp. extract compared to administration of isolated CBD and THC in decreasing allodynia and hyperalgesia in rats, evaluated by hot plate and von Frey tests (Comelli et al., 2008; Casey et al., 2017; Harris et al., 2019). Indeed, Comelli et al. (2008) described that the improvement in hyperalgesia through the use of Cannabis sp. extract was not affected by the use of cannabinoid receptor antagonists, reinforcing the fact that phytocannabinoids and other compounds in 
the extract act synergistically modulating several receptors and pathways. Additionally, the administration of a $1: 1$ CBD:THC extract has been described to positively modulate $\mathrm{CD} 4+$ lymphocytes in the spleen and thymus of female rats submitted to a nerve cuffed model for chronic neuropathic pain, which suggests that Cannabis sp. extract may also modulate immune response in the CNS related to chronic neuropathic pain development (Linher-Melville et al., 2020).

Patients consume medical Cannabis sp. products through different administration routes, such as smoked, vaporized, oromucosal aerosol, oily extract and capsules, although some studies describe that inhaling procedures can present health risks for patients (Aviram and Samuelly-Leichtag, 2017; Maayah et al., 2020). As described in animal studies, tests showed that Cannabis sp. full extract, such as Sativex ${ }^{\circledR}$, an oromucosal spray of 1:1 CBD:THC, was more effective for treating chronic neuropathic pain than synthetic THC, such as Dronabinol (Cannabis-In-Cachexia-Study-Group et al., 2006; Langford et al., 2013; Ferrè et al., 2016; Schimrigk et al., 2017). Nurmikko et al. (2007) coordinated a randomized, double-blind, placebocontrolled study to evaluate the analgesic properties of a THC:CBD (1:1) extract in 125 patients that had peripheral neuropathic pain symptoms. During the treatment with the extract, individuals continued with other analgesic medication previously prescribed. Sixty-three patients were in the placebo group, while 62 made use of the extract and were able to determine their own dose, although none of them had more than 48 spray doses per day. The group that was treated with the extract showed better results in pain scores, dynamic allodynia, punctual allodynia when compared to patients from the other group. An appendix of the study evaluated the same patients for 52 weeks and continued to observe the analgesic effect of the extract without dose adjustment or toxicity symptoms.

A more complete and recent study from the Germain Pain e-registry digital platform collected anonymous information related to the therapeutic approaches used for pain management (Ueberall et al., 2019). Using the answers from a Pain Detect Questionnaire 7 (PDQ7), patients were grouped with nociceptive, mixed and chronic neuropathic pain. Individuals used 1:1 CBD:THC Sativex ${ }^{\circledR}$ oromucosal spray, 8-12 times/day, for 12 weeks. After 3 months of Cannabis sp. spray use, the pain intensity decreased at least half in $67.5 \%$ of the patients, having a better effect in neuropathic and mixed pain patients. Another important information from this study consists in improved patient's welfare after Cannabis sp. treatment. This was measured by the Aggregated 9-Factor Symptom Relief (ASR-9) questionnaire. Fifteen percent of the individuals in the study improved at least $50 \%$ of all 9 factors and $56 \%$ of the patients improved at least 5 factors, such as stress, depression, well-being and anxiety, and again, the improvement was higher in neuropathic and mixed pain patients.

Another advantage to the use of Cannabis-derived products is the significant decrease or even elimination of other drugs, such as opioids, from the therapy scheme, known for having severe adverse effects. As described by Ueberall et al. (2019), a significant number of patients stopped using strong opioids as analgesic strategy 12 weeks after using Cannabis sp. extracts. Other clinical and animal researches describe similar results in opioid-based therapies after the use of Cannabis sp. extracts (Williams et al., 2008; Okusanya et al., 2020; Takakuwa and Sulak, 2020).

Together with the relief of symptoms, adverse effects are often described by patients under use of medicinal cannabis. The most common are gastrointestinal disorders, metabolism and nutrition disorders, increased appetite, sedation, fatigue, dry mouth, dizziness, and nausea (Nurmikko et al., 2007; Lynch et al., 2014; Ueberall et al., 2019). Few patients described adverse effects related to the psychoactive properties of THC. One patient described anxiety, panic attack, and confusion in the Lynch study (Lynch et al., 2014) and only 3.6\% of patients described anxiety, confusion, and disorientation in the Germain Pain e-registry based study (Ueberall et al., 2019), while, in Nurmikko et al. (2007), no psychoactive symptoms were listed by the participants. In general, most of the adverse effects are mild to moderate and are directly related to the dosage of THC in the product used in these researchers, besides the modulation of eCS in other organs and systems. However, it is important to highlight that in all clinical studies cited, patients with a history of psychotic disorder were excluded from the study.

\section{DISCUSSION}

Chronic neuropathic pain is a pathology that affects not only many individuals worldwide, but also their caregivers (Ojeda et al., 2014). Even though opioids are the main pharmacotherapeutic approach to reduce symptoms associated with chronic neuropathic pain, several reports describe its potential of inducing addiction and, as consequence, increasing mortality (Hser et al., 2015). In order to avoid side effects similar to those induced by opioids and have increased success in managing pain, new molecular targets are being continuously investigated for treatment of neuropathic chronic pain.

In this review, we describe how the eCS modulates the pathophysiological processing of pain, focusing mostly on animal models of chronic neuropathic pain and clinical trials. Several strategies have been developed to assess eCS role in chronic neuropathic pain management, such as the use of synthetic cannabinoid receptors agonists and degradation enzyme inhibitors, which have shown promising results in animal models. Unfortunately, it is not always possible to translate preclinical data into successful clinical application. As an example, the use of FAAH inhibitors, which showed positive results in many animal models, led to severe adverse effects and even death of a volunteer in a clinical trial (Mallet et al., 2016).

The use of Cannabis-based products is recommended as extracts, for instance Sativex ${ }^{\circledR}$. Although some synthetic cannabinoids may also be indicated for pain treatment, such as Dronabinol and Nabilone, the use of medicinal Cannabis sp. has recently increased substantially, improving pain management and inducing fewer side effects (Mücke et al., 2018). Despite this evidence, the IASP states that it lacks reliable clinical studies about the use of phytocannabinoids and medicinal Cannabis sp. 
to treat chronic pain (IASP Presidential Task Force on Cannabis and Cannabinoid Analgesia, 2021). Besides, there is little preclinical research that investigates the effect of Cannabis sp. extracts, the latter more commonly used by patients.

The role of eCS as a pharmacological target and the advantages of using medicinal Cannabis sp. to treat pain is remarkable, as described in this review. However, further investigation must be performed using animal models and in clinical practice to understand more efficient ways to modulate the eCS in humans and to identify how the entourage effect may contribute to the potential of Cannabis-based treatments in pain management.

\section{AUTHOR CONTRIBUTIONS}

RC, AA, YP-C, and PT wrote different sections of the review. $\mathrm{BF}$ also designed the original figures from this manuscript. $\mathrm{RM}$ and LS also provided the intellectual assistance, reviewed, and

\section{REFERENCES}

Abraham, A. D., Leung, E. J. Y., Wong, B. A., Rivera, Z. M. G., Kruse, L. C., Clark, J. J., et al. (2020). Orally consumed cannabinoids provide longlasting relief of allodynia in a mouse model of chronic neuropathic pain. Neuropsychopharmacology 45, 1105-1114. doi: 10.1038/s41386-019-0585-3

Ahrens, J., Demir, R., Leuwer, M., de la Roche, J., Krampfl, K., Foadi, N., et al. (2009). The nonpsychotropic cannabinoid cannabidiol modulates and directly activates alpha-1 and alpha-1-beta glycine receptor function. Pharmacology 83, 217-222. doi: 10.1159/000201556

Alles, S. R. A., and Smith, P. A. (2018). Etiology and pharmacology of neuropathic pain. Pharmacol. Rev. 70, 315-347. doi: 10.1124/pr.117.014399

Attal, N., Cruccu, G., Baron, R., Haanpää, M., Hansson, P., Jensen, T. S., et al. (2010). EFNS guidelines on the pharmacological treatment of neuropathic pain: 2010 revision. Eur. J. Neurol. 17, 1113-e88. doi: 10.1111/j.1468-1331.2010. 02999.x

Aviram, J., and Samuelly-Leichtag, G. (2017). Efficacy of Cannabis-based medicines for pain management: a systematic review and meta-analysis of randomized controlled trials. Pain Physician 20, E755-E796.

Befort, K. (2015). Interactions of the opioid and cannabinoid systems in reward: insights from knockout studies. Front. Pharmacol. 6:6. doi: 10.3389/fphar.2015. 00006

Benowitz, N. L., Nguyen, T. L., Jones, R. T., Herning, R. I., and Bachman, J. (1980). Metabolic and psychophysiologic studies of cannabidiol-hexobarbital interaction. Clin. Pharmacol. Ther. 28, 115-120. doi: 10.1038/clpt.1980.139

Bisogno, T., Hanus, L., De Petrocellis, L., Tchilibon, S., Ponde, D. E., Brandi, I., et al. (2001). Molecular targets for cannabidiol and its synthetic analogues: effect on vanilloid VR1 receptors and on the cellular uptake and enzymatic hydrolysis of anandamide. Br. J. Pharmacol. 134, 845-852. doi: 10.1038/sj.bjp.0704327

Bonini, S. A., Premoli, M., Tambaro, S., Kumar, A., Maccarinelli, G., Memo, M., et al. (2018). Cannabis sativa: a comprehensive ethnopharmacological review of a medicinal plant with a long history. J. Ethnopharmacol. 227, 300-315. doi: 10.1016/j.jep.2018.09.004

Bridges, D., Ahmad, K., and Rice, A. S. (2001). The synthetic cannabinoid WIN55,212-2 attenuates hyperalgesia and allodynia in a rat model of neuropathic pain. Br. J. Pharmacol. 133, 586-594. doi: 10.1038/sj.bjp.0704110

Burgos, E., Gómez-Nicola, D., Pascual, D., Martín, M. I., Nieto-Sampedro, M., and Goicoechea, C. (2012). Cannabinoid agonist WIN 55,212-2 prevents the development of paclitaxel-induced peripheral neuropathy in rats. Possible involvement of spinal glial cells. Eur. J. Pharmacol. 682, 62-72. doi: 10.1016/ j.ejphar.2012.02.008

Burstein, S., Levin, E., and Varanelli, C. (1973). Prostaglandins and cannabis. II. Inhibition of biosynthesis by the naturally occurring cannabinoids. Biochem. Pharmacol. 22, 2905-2910. doi: 10.1016/0006-2952(73)90158-5 corrected the manuscript. All authors performed the literature revision need for this review and approved the submitted version.

\section{FUNDING}

This study was supported by the Coordenação de Aperfeiçoamento de Pessoal de Nível Superior (CAPES), Fundação Carlos Chagas Filho de Amparo à Pesquisa do Estado do Rio de Janeiro (FAPERJ), and Conselho Nacional de Desenvolvimento Científico e Tecnológico (CNPq), LS was supported by FAPERJ, grant number E26/202.997/2019; RM was supported by FAPERJ, grant numbers E-26/202.668/2018 and E-26/010.002215/2019; grant numbers 426342/2018-6 and 312157/2016-9; INCT-INNT (National Institute for Translational Neuroscience); and RC was supported by CAPES, grant number 88887.360870/ 2019-00.

Cannabis-In-Cachexia-Study-Group, Strasser, F., Luftner, D., Possinger, K., Ernst, G., Ruhstaller, T., et al. (2006). Comparison of orally administered cannabis extract and delta-9-tetrahydrocannabinol in treating patients with cancerrelated anorexia-cachexia syndrome: a multicenter, phase III, randomized, double-blind, placebo-controlled clinical trial from the Cannabis-In-CachexiaStudy-Group. J. Clin. Oncol. 24, 3394-3400. doi: 10.1200/JCO.2005.05. 1847

Caprioli, A., Coccurello, R., Rapino, C., Di Serio, S., Di Tommaso, M., Vertechy, M., et al. (2012). The novel reversible fatty acid amide hydrolase inhibitor ST4070 increases endocannabinoid brain levels and counteracts neuropathic pain in different animal models. J. Pharmacol. Exp. Ther. 342, 188-195. doi: 10.1124/jpet.111.191403

Carlini, E. A., Karniol, I. G., Renault, P. F., and Schuster, C. R. (1974). Effects of marihuana in laboratory animals and in man. Br. J. Pharmacol. 50, 299-309. doi: 10.1111/j.1476-5381.1974.tb08576.x

Casey, S. L., Atwal, N., and Vaughan, C. W. (2017). Cannabis constituent synergy in a mouse neuropathic pain model. Pain 158, 2452-2460. doi: 10.1097/j.pain. 0000000000001051

Cata, J. P., Weng, H. R., Chen, J. H., and Dougherty, P. M. (2006). Altered discharges of spinal wide dynamic range neurons and downregulation of glutamate transporter expression in rats with paclitaxel-induced hyperalgesia. Neuroscience 138, 329-338. doi: 10.1016/j.neuroscience.2005. 11.009

Caterina, M. J., Rosen, T. A., Tominaga, M., Brake, A. J., and Julius, D. (1999). A capsaicin-receptor homologue with a high threshold for noxious heat. Nature 398, 436-441. doi: 10.1038/18906

CDC (2021). Understanding the Epidemic. Available online at: https://www.cdc. gov/opioids/basics/epidemic.html (accessed October 30, 2021).

Choi, B. M., Lee, S. H., An, S. M., Park, D. Y., Lee, G. W., and Noh, G. J. (2015). Corrigendum: the time-course and RNA interference of TNF- $\alpha$, IL- 6 , and IL-1 $\beta$ expression on neuropathic pain induced by L5 spinal nerve transection in rats (Korean J Anesthesiol 2015 April 68(2): 159-169). Korean J. Anesthesiol. 68:311. doi: 10.4097/kjae.2015.68.3.311

Chouinard, F., Lefebvre, J. S., Navarro, P., Bouchard, L., Ferland, C., LalancetteHébert, M., et al. (2011). The endocannabinoid 2-arachidonoyl-glycerol activates human neutrophils: critical role of its hydrolysis and de novo leukotriene B4 biosynthesis. J. Immunol. 186, 3188-3196. doi: 10.4049/ jimmunol.1002853

Clapper, J. R., Moreno-Sanz, G., Russo, R., Guijarro, A., Vacondio, F., Duranti, A., et al. (2010). Anandamide suppresses pain initiation through a peripheral endocannabinoid mechanism. Nat. Neurosci. 13, 1265-1270. doi: 10.1038/nn. 2632

Cohen, S. P., and Mao, J. (2014). Neuropathic pain: mechanisms and their clinical implications. BMJ 348:f7656. doi: 10.1136/bmj.f7656 
Colloca, L., Ludman, T., Bouhassira, D., Baron, R., Dickenson, A. H., Yarnitsky, D., et al. (2017). Neuropathic pain. Nat. Rev. Dis. Primers 3:17002. doi: 10.1038/ nrdp. 2017.2

Comelli, F., Giagnoni, G., Bettoni, I., Colleoni, M., and Costa, B. (2008). Antihyperalgesic effect of a Cannabis sativa extract in a rat model of neuropathic pain: mechanisms involved. Phytother. Res. 22, 1017-1024. doi: 10.1002/ptr.2401

Cristino, L., Bisogno, T., and Di Marzo, V. (2020). Cannabinoids and the expanded endocannabinoid system in neurological disorders. Nat. Rev. Neurol. 16, 9-29. doi: 10.1038/s41582-019-0284-z

Crunfli, F., Vilela, F. C., and Giusti-Paiva, A. (2015). Cannabinoid CB1 receptors mediate the effects of dipyrone. Clin. Exp. Pharmacol. Physiol. 42, 246-255. doi: 10.1111/1440-1681.12347

D’Arco, M., Margas, W., Cassidy, J. S., and Dolphin, A. C. (2015). The upregulation of $\alpha 2 \delta-1$ subunit modulates activity-dependent $\mathrm{Ca}^{2+}$ signals in sensory neurons. J. Neurosci. 35, 5891-5903. doi: 10.1523/jneurosci.3997-14.2015

Davis, M. P. (2014). Cannabinoids in pain management: CB1, CB2 and non-classic receptor ligands. Expert Opin. Investig. Drugs 23, 1123-1140. doi: 10.1517/ 13543784.2014.918603

Davoli-Ferreira, M., de Lima, K. A., Fonseca, M. M., Guimarães, R. M., Gomes, F. I., Cavallini, M. C., et al. (2020). Regulatory T cells counteract neuropathic pain through inhibition of the Th1 response at the site of peripheral nerve injury. Pain 161, 1730-1743. doi: 10.1097/j.pain.0000000000001879

De Petrocellis, L., Starowicz, K., Moriello, A. S., Vivese, M., Orlando, P., and Di Marzo, V. (2007). Regulation of transient receptor potential channels of melastatin type 8 (TRPM8): effect of cAMP, cannabinoid $\mathrm{CB}(1)$ receptors and endovanilloids. Exp. Cell Res. 313, 1911-1920. doi: 10.1016/j.yexcr.2007.01.008

De Petrocellis, L., Vellani, V., Schiano-Moriello, A., Marini, P., Magherini, P. C., Orlando, P., et al. (2008). Plant-derived cannabinoids modulate the activity of transient receptor potential channels of ankyrin type- 1 and melastatin type-8. J. Pharmacol. Exp. Ther. 325, 1007-1015. doi: 10.1124/jpet.107.134809

De Vry, J., Kuhl, E., Franken-Kunkel, P., and Eckel, G. (2004). Pharmacological characterization of the chronic constriction injury model of neuropathic pain. Eur. J. Pharmacol. 491, 137-148. doi: 10.1016/j.ejphar.2004.03.051

Desroches, J., Guindon, J., Lambert, C., and Beaulieu, P. (2008). Modulation of the anti-nociceptive effects of 2-arachidonoyl glycerol by peripherally administered FAAH and MGL inhibitors in a neuropathic pain model. Br. J. Pharmacol. 155, 913-924. doi: 10.1038/bjp.2008.322

Di Marzo, V., and Piscitelli, F. (2015). The endocannabinoid system and its modulation by phytocannabinoids. Neurotherapeutics 12, 692-698. doi: 10 . 1007/s13311-015-0374-6

D’Mello, R., and Dickenson, A. H. (2008). Spinal cord mechanisms of pain. Br. J. Anaesth. 101, 8-16. doi: 10.1093/bja/aen088

Dworkin, R. H., O’Connor, A. B., Audette, J., Baron, R., Gourlay, G. K., Haanpää, M. L., et al. (2010). Recommendations for the pharmacological management of neuropathic pain: an overview and literature update. Mayo Clin. Proc. 85(Suppl. 3), S3-S14. doi: 10.4065/mcp.2009.0649

Farquhar-Smith, W. P., Egertová, M., Bradbury, E. J., McMahon, S. B., Rice, A. S., and Elphick, M. R. (2000). Cannabinoid CB(1) receptor expression in rat spinal cord. Mol. Cell. Neurosci. 15, 510-521. doi: 10.1006/mcne.2000.0844

Ferrè, L., Nuara, A., Pavan, G., Radaelli, M., Moiola, L., Rodegher, M., et al. (2016). Efficacy and safety of nabiximols (Sativex $\left({ }^{\circledR}\right)$ ) on multiple sclerosis spasticity in a real-life Italian monocentric study. Neurol. Sci. 37, 235-242. doi: 10.1007/s10072-015-2392-x

Finn, D. P., Haroutounian, S., Hohmann, A. G., Krane, E., Soliman, N., and Rice, A. S. C. (2021). Cannabinoids, the endocannabinoid system, and pain: a review of preclinical studies. Pain 162(Suppl. 1), S5-S25. doi: 10.1097/j.pain. 0000000000002268

Finnerup, N. B., Attal, N., Haroutounian, S., McNicol, E., Baron, R., Dworkin, R. H., et al. (2015). Pharmacotherapy for neuropathic pain in adults: a systematic review and meta-analysis. Lancet Neurol. 14, 162-173. doi: 10.1016/ s1474-4422(14)70251-0

Fornasari, D. (2017). Pharmacotherapy for neuropathic pain: a review. Pain Ther. 6(Suppl. 1), 25-33. doi: 10.1007/s40122-017-0091-4

Foster, E., Wildner, H., Tudeau, L., Haueter, S., Ralvenius, W. T., Jegen, M., et al. (2015). Targeted ablation, silencing, and activation establish glycinergic dorsal horn neurons as key components of a spinal gate for pain and itch. Neuron 85 , 1289-1304. doi: 10.1016/j.neuron.2015.02.028
Frank, B., Serpell, M. G., Hughes, J., Matthews, J. N., and Kapur, D. (2008). Comparison of analgesic effects and patient tolerability of nabilone and dihydrocodeine for chronic neuropathic pain: randomised, crossover, double blind study. BMJ 336, 199-201. doi: 10.1136/bmj.39429.619653.80

García-Gutiérrez, M. S., Navarrete, F., Gasparyan, A., Austrich-Olivares, A., Sala, F., and Manzanares, J. (2020). Cannabidiol: a potential new alternative for the treatment of anxiety, depression, and psychotic disorders. Biomolecules 10:1575. doi: 10.3390/biom10111575

Gertsch, J., Leonti, M., Raduner, S., Racz, I., Chen, J. Z., Xie, X. Q., et al. (2008). Beta-caryophyllene is a dietary cannabinoid. Proc. Natl. Acad. Sci. U.S.A. 105, 9099-9104. doi: 10.1073/pnas.0803601105

Greineisen, W. E., and Turner, H. (2010). Immunoactive effects of cannabinoids: considerations for the therapeutic use of cannabinoid receptor agonists and antagonists. Int. Immunopharmacol. 10, 547-555. doi: 10.1016/j.intimp.2010. 02.012

Grinspoon, L., and Bakalar, J. B. (1993). Marihuana, the Forbidden Medicine. New Haven, CT: Yale University Press.

Gui, Y., Zhang, J., Chen, L., Duan, S., Tang, J., Xu, W., et al. (2018). Icariin, a flavonoid with anti-cancer effects, alleviated paclitaxel-induced neuropathic pain in a SIRT1-dependent manner. Mol. Pain 14:1744806918768970. doi: $10.1177 / 1744806918768970$

Guindon, J., and Beaulieu, P. (2006). Antihyperalgesic effects of local injections of anandamide, ibuprofen, rofecoxib and their combinations in a model of neuropathic pain. Neuropharmacology 50, 814-823. doi: 10.1016/j. neuropharm.2005.12.002

Guindon, J., Lai, Y., Takacs, S. M., Bradshaw, H. B., and Hohmann, A. G. (2013). Alterations in endocannabinoid tone following chemotherapyinduced peripheral neuropathy: effects of endocannabinoid deactivation inhibitors targeting fatty-acid amide hydrolase and monoacylglycerol lipase in comparison to reference analgesics following cisplatin treatment. Pharmacol. Res. 67, 94-109. doi: 10.1016/j.phrs.2012.10.013

Habib, A. M., Okorokov, A. L., Hill, M. N., Bras, J. T., Lee, M. C., Li, S., et al. (2019). Microdeletion in a FAAH pseudogene identified in a patient with high anandamide concentrations and pain insensitivity. Br. J. Anaesth. 123, e249-e253. doi: 10.1016/j.bja.2019.02.019

Harris, H. M., Rousseau, M. A., Wanas, A. S., Radwan, M. M., Caldwell, S., Sufka, K. J., et al. (2019). Role of cannabinoids and terpenes in cannabis-mediated analgesia in rats. Cannabis Cannabinoid Res. 4, 177-182. doi: 10.1089/can.2018. 0054

Harris, H. M., Sufka, K. J., Gul, W., and ElSohly, M. A. (2016). Effects of delta9-tetrahydrocannabinol and cannabidiol on cisplatin-induced neuropathy in mice. Planta Med. 82, 1169-1172. doi: 10.1055/s-0042-106303

Hegyi, Z., Kis, G., Holló, K., Ledent, C., and Antal, M. (2009). Neuronal and glial localization of the cannabinoid-1 receptor in the superficial spinal dorsal horn of the rodent spinal cord. Eur. J. Neurosci. 30, 251-262. doi: 10.1111/j.14609568.2009.06816.x

Hennemann-Krause, L., and Sredni, S. (2016). Systemic drug therapy for neuropathic pain. Revista Dor 17(Suppl. 1), 91-94. doi: 10.5935/1806-0013. 20160057

Hohmann, A. G., Briley, E. M., and Herkenham, M. (1999). Pre- and postsynaptic distribution of cannabinoid and mu opioid receptors in rat spinal cord. Brain Res. 822, 17-25. doi: 10.1016/s0006-8993(98)01321-3

Howlett, A. C., Barth, F., Bonner, T. I., Cabral, G., Casellas, P., Devane, W. A., et al. (2002). International Union of Pharmacology. XXVII. Classification of cannabinoid receptors. Pharmacol. Rev. 54, 161-202. doi: 10.1124/pr.54.2.161

Hser, Y. I., Evans, E., Grella, C., Ling, W., and Anglin, D. (2015). Long-term course of opioid addiction. Harv. Rev. Psychiatry 23, 76-89. doi: 10.1097/HRP. 0000000000000052

IASP Presidential Task Force on Cannabis and Cannabinoid Analgesia (2021). International Association for the Study of Pain presidential task force on cannabis and cannabinoid Analgesia position statement. Pain 162(Suppl. 1), S1-S2. doi: 10.1097/j.pain.0000000000002265

Immke, D. C., and Gavva, N. R. (2006). The TRPV1 receptor and nociception. Semin. Cell. Dev. Biol. 17, 582-591. doi: 10.1016/j.semcdb.2006.09.004

Janssen, S. P., Truin, M., Van Kleef, M., and Joosten, E. A. (2011). Differential GABAergic disinhibition during the development of painful peripheral neuropathy. Neuroscience 184, 183-194. doi: 10.1016/j.neuroscience.2011. 03.060 
Jones, G., and Pertwee, R. G. (1972). A metabolic interaction in vivo between cannabidiol and 1 -tetrahydrocannabinol. Br. J. Pharmacol. 45, 375-377. doi: 10.1111/j.1476-5381.1972.tb08092.x

Katona, I., Rancz, E. A., Acsady, L., Ledent, C., Mackie, K., Hajos, N., et al. (2001). Distribution of CB1 cannabinoid receptors in the amygdala and their role in the control of GABAergic transmission. J. Neurosci. 21, 9506-9518. doi: 10.1523/JNEUROSCI.21-23-09506.2001

King, K. M., Myers, A. M., Soroka-Monzo, A. J., Tuma, R. F., Tallarida, R. J., Walker, E. A., et al. (2017). Single and combined effects of $\Delta(9)$ tetrahydrocannabinol and cannabidiol in a mouse model of chemotherapyinduced neuropathic pain. Br. J. Pharmacol. 174, 2832-2841. doi: 10.1111/bph. 13887

Klauke, A. L., Racz, I., Pradier, B., Markert, A., Zimmer, A. M., Gertsch, J., et al. (2014). The cannabinoid CB2 receptor-selective phytocannabinoid betacaryophyllene exerts analgesic effects in mouse models of inflammatory and neuropathic pain. Eur. Neuropsychopharmacol. 24, 608-620. doi: 10.1016/j. euroneuro.2013.10.008

Kleinschnitz, C., Hofstetter, H. H., Meuth, S. G., Braeuninger, S., Sommer, C., and Stoll, G. (2006). T cell infiltration after chronic constriction injury of mouse sciatic nerve is associated with interleukin-17 expression. Exp. Neurol. 200, 480-485. doi: 10.1016/j.expneurol.2006.03.014

Knaster, P., Karlsson, H., Estlander, A. M., and Kalso, E. (2012). Psychiatric disorders as assessed with SCID in chronic pain patients: the anxiety disorders precede the onset of pain. Gen. Hosp. Psychiatry 34, 46-52. doi: 10.1016/j. genhosppsych.2011.09.004

Kozak, K. R., Gupta, R. A., Moody, J. S., Ji, C., Boeglin, W. E., DuBois, R. N., et al. (2002). 15-Lipoxygenase metabolism of 2-arachidonylglycerol. Generation of a peroxisome proliferator-activated receptor alpha agonist. J. Biol. Chem. 277, 23278-23286. doi: 10.1074/jbc.M201084200

Kuner, R., and Flor, H. (2017). Structural plasticity and reorganisation in chronic pain. Nat. Rev. Neurosci. 18:113. doi: 10.1038/nrn.2017.5

Langford, R. M., Mares, J., Novotna, A., Vachova, M., Novakova, I., Notcutt, W., et al. (2013). A double-blind, randomized, placebo-controlled, parallelgroup study of THC/CBD oromucosal spray in combination with the existing treatment regimen, in the relief of central neuropathic pain in patients with multiple sclerosis. J. Neurol. 260, 984-997. doi: 10.1007/s00415-0126739-4

Lauria, G., Morbin, M., Lombardi, R., Capobianco, R., Camozzi, F., Pareyson, D., et al. (2006). Expression of capsaicin receptor immunoreactivity in human peripheral nervous system and in painful neuropathies. J. Peripher. Nerv Syst. 11, 262-271. doi: 10.1111/j.1529-8027.2006.0097.x

Le Pichon, C. E., and Chesler, A. T. (2014). The functional and anatomical dissection of somatosensory subpopulations using mouse genetics. Front. Neuroanat. 8:21. doi: 10.3389/fnana.2014.00021

Legrain, V., Iannetti, G. D., Plaghki, L., and Mouraux, A. (2011). The pain matrix reloaded: a salience detection system for the body. Prog. Neurobiol. 93, 111-124. doi: 10.1016/j.pneurobio.2010.10.005

Li, C. Y., Song, Y. H., Higuera, E. S., and Luo, Z. D. (2004). Spinal dorsal horn calcium channel alpha2delta-1 subunit upregulation contributes to peripheral nerve injury-induced tactile allodynia. J. Neurosci. 24, 8494-8499. doi: 10.1523/ jneurosci.2982-04.2004

Li, X. J., Yang, Y. J., Li, Y. S., Zhang, W. K., and Tang, H. B. (2016). $\alpha-$ Pinene, linalool, and 1-octanol contribute to the topical anti-inflammatory and analgesic activities of frankincense by inhibiting COX-2. J. Ethnopharmacol. 179, 22-26. doi: 10.1016/j.jep.2015.12.039

Linher-Melville, K., Zhu, Y. F., Sidhu, J., Parzei, N., Shahid, A., Seesankar, G., et al. (2020). Evaluation of the preclinical analgesic efficacy of naturally derived, orally administered oil forms of $\Delta 9$-tetrahydrocannabinol (THC), cannabidiol (CBD), and their 1:1 combination. PLoS One 15:e0234176. doi: 10.1371/journal. pone. 0234176

Lorenzetti, B. B., Souza, G. E., Sarti, S. J., Santos Filho, D., and Ferreira, S. H. (1991). Myrcene mimics the peripheral analgesic activity of lemongrass tea. J. Ethnopharmacol. 34, 43-48. doi: 10.1016/0378-8741(91)90187-i

Lynch, M. E., Cesar-Rittenberg, P., and Hohmann, A. G. (2014). A double-blind, placebo-controlled, crossover pilot trial with extension using an oral mucosal cannabinoid extract for treatment of chemotherapy-induced neuropathic pain. J. Pain Symptom Manage. 47, 166-173. doi: 10.1016/j.jpainsymman.2013. 02.018
Maayah, Z. H., Takahara, S., Ferdaoussi, M., and Dyck, J. R. B. (2020). The molecular mechanisms that underpin the biological benefits of full-spectrum cannabis extract in the treatment of neuropathic pain and inflammation. Biochim. Biophys. Acta Mol. Basis Dis. 1866:165771. doi: 10.1016/j.bbadis.2020. 165771

Maccarrone, M., Bab, I., Bíró, T., Cabral, G. A., Dey, S. K., Di Marzo, V., et al. (2015). Endocannabinoid signaling at the periphery: 50 years after THC. Trends Pharmacol. Sci. 36, 277-296. doi: 10.1016/j.tips.2015.02.008

Malek, N., Kucharczyk, M., and Starowicz, K. (2014). Alterations in the anandamide metabolism in the development of neuropathic pain. Biomed. Res. Int. 2014:686908. doi: 10.1155/2014/686908

Mallet, C., Dubray, C., and Dualé, C. (2016). FAAH inhibitors in the limelight, but regrettably. Int. J. Clin. Pharmacol. Ther. 54, 498-501. doi: 10.5414/cp202687

Massi, P., Valenti, M., Vaccani, A., Gasperi, V., Perletti, G., Marras, E., et al. (2008). 5-Lipoxygenase and anandamide hydrolase (FAAH) mediate the antitumor activity of cannabidiol, a non-psychoactive cannabinoid. J. Neurochem. 104, 1091-1100. doi: 10.1111/j.1471-4159.2007.05073.x

McPartland, J., and Russo, E. (2001). Cannabis and cannabis extracts: greater than the sum of their parts? J. Cannabis Ther. 1, 103-132. doi: 10.1300/J175v01n 03_08

Meacham, K., Shepherd, A., Mohapatra, D. P., and Haroutounian, S. (2017). Neuropathic pain: central vs. Peripheral mechanisms. Curr. Pain Headache Rep. 21:28. doi: 10.1007/s11916-017-0629-5

Mecca, C. M., Chao, D., Yu, G., Feng, Y., Segel, I., Zhang, Z., et al. (2021). Dynamic change of endocannabinoid signaling in the medial prefrontal cortex controls the development of depression after neuropathic pain. J. Neurosci. 41, 7492-7508. doi: 10.1523/JNEUROSCI.3135-20.2021

Mecha, M., Feliú, A., Carrillo-Salinas, F. J., Rueda-Zubiaurre, A., Ortega-Gutiérrez, S., de Sola, R. G., et al. (2015). Endocannabinoids drive the acquisition of an alternative phenotype in microglia. Brain Behav. Immun. 49, 233-245. doi: 10.1016/j.bbi.2015.06.002

Moore, K. A., Kohno, T., Karchewski, L. A., Scholz, J., Baba, H., and Woolf, C. J. (2002). Partial peripheral nerve injury promotes a selective loss of GABAergic inhibition in the superficial dorsal horn of the spinal cord. J. Neurosci. 22, 6724-6731. doi: 10.1523/jneurosci.22-15-06724.2002

Moore, R. A., and McQuay, H. J. (2005). Prevalence of opioid adverse events in chronic non-malignant pain: systematic review of randomised trials of oral opioids. Arthritis Res. Ther. 7, R1046-R1051. doi: 10.1186/ar1782

Moulin, D., Boulanger, A., Clark, A. J., Clarke, H., Dao, T., Finley, G. A., et al. (2014). Pharmacological management of chronic neuropathic pain: revised consensus statement from the Canadian Pain Society. Pain Res. Manag. 19, 328-335. doi: 10.1155/2014/754693

Mücke, M., Phillips, T., Radbruch, L., Petzke, F., and Häuser, W. (2018). Cannabisbased medicines for chronic neuropathic pain in adults. Cochrane Database Syst. Rev. 3:Cd012182. doi: 10.1002/14651858.CD012182.pub2

Nadipelly, J., Sayeli, V., Kadhirvelu, P., Shanmugasundaram, J., Cheriyan, B. V., and Subramanian, V. (2018). Effect of certain trimethoxy flavones on paclitaxel - induced peripheral neuropathy in mice. Integr. Med. Res. 7, 159-167. doi: 10.1016/j.imr.2018.03.006

Narang, S., Gibson, D., Wasan, A. D., Ross, E. L., Michna, E., Nedeljkovic, S. S., et al. (2008). Efficacy of dronabinol as an adjuvant treatment for chronic pain patients on opioid therapy. J. Pain 9, 254-264. doi: 10.1016/j.jpain.2007. 10.018

Niu, J., Huang, D., Zhou, R., Yue, M., Xu, T., Yang, J., et al. (2017). Activation of dorsal horn cannabinoid CB2 receptor suppresses the expression of P2Y(12) and $\mathrm{P} 2 \mathrm{Y}(13)$ receptors in neuropathic pain rats. J. Neuroinflammation 14:185. doi: 10.1186/s12974-017-0960-0

Nurmikko, T. J., Serpell, M. G., Hoggart, B., Toomey, P. J., Morlion, B. J., and Haines, D. (2007). Sativex successfully treats neuropathic pain characterised by allodynia: a randomised, double-blind, placebo-controlled clinical trial. Pain 133, 210-220. doi: 10.1016/j.pain.2007.08.028

Ojeda, B., Salazar, A., Dueñas, M., Torres, L. M., Micó, J. A., and Failde, I. (2014). The impact of chronic pain: the perspective of patients, relatives, and caregivers. Fam. Syst. Health 32, 399-407. doi: 10.1037/fsh0000069

Okusanya, B. O., Asaolu, I. O., Ehiri, J. E., Kimaru, L. J., Okechukwu, A., and Rosales, C. (2020). Medical cannabis for the reduction of opioid dosage in the treatment of non-cancer chronic pain: a systematic review. Syst. Rev. 9:167. doi: $10.1186 /$ s13643-020-01425-3 
Ossipov, M. H., Dussor, G. O., and Porreca, F. (2010). Central modulation of pain. J. Clin. Invest. 120, 3779-3787. doi: 10.1172/jci43766

Peng, J., Gu, N., Zhou, L., B Eyo, U., Murugan, M., Gan, W. B., et al. (2016). Microglia and monocytes synergistically promote the transition from acute to chronic pain after nerve injury. Nat. Commun. 7:12029. doi: 10.1038/ ncomms 12029

Pitcher, M. H., Von Korff, M., Bushnell, M. C., and Porter, L. (2019). Prevalence and profile of high-impact chronic pain in the United States. J. Pain. 20, 146-160. doi: 10.1016/j.jpain.2018.07.006

Price, T. J., Helesic, G., Parghi, D., Hargreaves, K. M., and Flores, C. M. (2003). The neuronal distribution of cannabinoid receptor type 1 in the trigeminal ganglion of the rat. Neuroscience 120, 155-162. doi: 10.1016/s0306-4522(03)00 333-6

Radat, F., Margot-Duclot, A., and Attal, N. (2013). Psychiatric co-morbidities in patients with chronic peripheral neuropathic pain: a multicentre cohort study. Eur. J. Pain 17, 1547-1557. doi: 10.1002/j.1532-2149.2013.00334.x

Rahn, E. J., Makriyannis, A., and Hohmann, A. G. (2007). Activation of cannabinoid $\mathrm{CB} 1$ and $\mathrm{CB} 2$ receptors suppresses neuropathic nociception evoked by the chemotherapeutic agent vincristine in rats. Br. J. Pharmacol. 152, 765-777. doi: 10.1038/sj.bjp.0707333

Raja, S. N., Carr, D. B., Cohen, M., Finnerup, N. B., Flor, H., Gibson, S., et al. (2020). The revised International Association for the Study of Pain definition of pain: concepts, challenges, and compromises. Pain 161, 1976-1982. doi: 10.1097/j.pain.0000000000001939

Rani Sagar, D., Burston, J. J., Woodhams, S. G., and Chapman, V. (2012). Dynamic changes to the endocannabinoid system in models of chronic pain. Philos. Trans. R. Soc. Lond. B Biol. Sci. 367, 3300-3311. doi: 10.1098/rstb.2011.0390

Rao, V. S., Menezes, A. M., and Viana, G. S. (1990). Effect of myrcene on nociception in mice. J. Pharm. Pharmacol. 42, 877-878. doi: 10.1111/j.20427158.1990.tb07046.x

Rexed, B. (1952). The cytoarchitectonic organization of the spinal cord in the cat. J. Comp. Neurol. 96, 414-495. doi: 10.1002/cne.900960303

Richardson, J. D., Aanonsen, L., and Hargreaves, K. M. (1997). SR 141716A, a cannabinoid receptor antagonist, produces hyperalgesia in untreated mice. Eur. J. Pharmacol. 319, R3-R4. doi: 10.1016/s0014-2999(96)00952-1

Romero-Sandoval, A., and Eisenach, J. C. (2007). Spinal cannabinoid receptor type 2 activation reduces hypersensitivity and spinal cord glial activation after paw incision. Anesthesiology 106, 787-794. doi: 10.1097/01.anes.0000264765.33673. $6 c$

Romero-Sandoval, A., Nutile-McMenemy, N., and DeLeo, J. A. (2008). Spinal microglial and perivascular cell cannabinoid receptor type 2 activation reduces behavioral hypersensitivity without tolerance after peripheral nerve injury. Anesthesiology 108, 722-734. doi: 10.1097/ALN.0b013e318167af74

Ruhaak, L. R., Felth, J., Karlsson, P. C., Rafter, J. J., Verpoorte, R., and Bohlin, L. (2011). Evaluation of the cyclooxygenase inhibiting effects of six major cannabinoids isolated from Cannabis sativa. Biol. Pharm. Bull. 34, 774-778. doi: $10.1248 / \mathrm{bpb} .34 .774$

Russo, E. B. (2008). Cannabinoids in the management of difficult to treat pain. Ther. Clin. Risk Manag. 4, 245-259. doi: 10.2147/tcrm.s1928

Russo, E. B., Burnett, A., Hall, B., and Parker, K. K. (2005). Agonistic properties of cannabidiol at 5-HT1a receptors. Neurochem. Res. 30, 1037-1043. doi: 10.1007/ s11064-005-6978-1

Salio, C., Fischer, J., Franzoni, M. F., and Conrath, M. (2002). Pre- and postsynaptic localizations of the CB1 cannabinoid receptor in the dorsal horn of the rat spinal cord. Neuroscience 110, 755-764. doi: 10.1016/s0306-4522(01)00584-x

Schimrigk, S., Marziniak, M., Neubauer, C., Kugler, E. M., Werner, G., and Abramov-Sommariva, D. (2017). Dronabinol is a safe long-term treatment option for neuropathic pain patients. Eur. Neurol. 78, 320-329. doi: 10.1159/ 000481089

Schlosburg, J. E., Radanova, L., Di Marzo, V., Imming, P., and Lichtman, A. H. (2012). Evaluation of the endogenous cannabinoid system in mediating the behavioral effects of dipyrone (metamizol) in mice. Behav. Pharmacol. 23, 722-726. doi: 10.1097/FBP.0b013e3283584794

Scott, D. A., Wright, C. E., and Angus, J. A. (2004). Evidence that CB-1 and CB-2 cannabinoid receptors mediate antinociception in neuropathic pain in the rat. Pain 109, 124-131. doi: 10.1016/j.pain.2004.01.020

Segat, G. C., Manjavachi, M. N., Matias, D. O., Passos, G. F., Freitas, C. S., Costa, R., et al. (2017). Antiallodynic effect of $\beta$-caryophyllene on paclitaxel-induced peripheral neuropathy in mice. Neuropharmacology 125, 207-219. doi: 10. 1016/j.neuropharm.2017.07.015

Shen, M., Piser, T. M., Seybold, V. S., and Thayer, S. A. (1996). Cannabinoid receptor agonists inhibit glutamatergic synaptic transmission in rat hippocampal cultures. J. Neurosci. 16, 4322-4334. doi: 10.1523/jneurosci. 16-14-04322.1996

Showalter, V. M., Compton, D. R., Martin, B. R., and Abood, M. E. (1996). Evaluation of binding in a transfected cell line expressing a peripheral cannabinoid receptor (CB2): identification of cannabinoid receptor subtype selective ligands. J. Pharmacol. Exp. Ther. 278, 989-999.

Silva-Cardoso, G. K., Lazarini-Lopes, W., Hallak, J. E., Crippa, J. A., Zuardi, A. W., Garcia-Cairasco, N., et al. (2021). Cannabidiol effectively reverses mechanical and thermal allodynia, hyperalgesia, and anxious behaviors in a neuropathic pain model: possible role of CB1 and TRPV1 receptors. Neuropharmacology 197:108712. doi: 10.1016/j.neuropharm.2021.108712

Snider, N. T., Nast, J. A., Tesmer, L. A., and Hollenberg, P. F. (2009). A cytochrome P450-derived epoxygenated metabolite of anandamide is a potent cannabinoid receptor 2-selective agonist. Mol. Pharmacol. 75, 965-972. doi: 10.1124/mol. 108.053439

Starowicz, K., and Finn, D. P. (2017). Cannabinoids and pain: sites and mechanisms of action. Adv. Pharmacol. 80, 437-475. doi: 10.1016/bs.apha. 2017.05.003

Stasiulewicz, A., Znajdek, K., Grudzień, M., Pawiński, T., and Sulkowska, A. (2020). A guide to targeting the endocannabinoid system in drug design. Int. J. Mol. Sci. 21:2778. doi: $10.3390 / \mathrm{ijms} 21082778$

Stella, N. (2009). Endocannabinoid signaling in microglial cells. Neuropharmacology 56(Suppl. 1), 244-253. doi: 10.1016/j.neuropharm. 2008.07.037

Stemkowski, P. L., Garcia-Caballero, A., Gadotti, V. M., M'Dahoma, S., Chen, L., Souza, I. A., et al. (2017). Identification of interleukin-1 beta as a key mediator in the upregulation of Cav3.2-USP5 interactions in the pain pathway. Mol. Pain 13:1744806917724698. doi: 10.1177/1744806917724698

Storozhuk, M. V., and Zholos, A. V. (2018). TRP channels as novel targets for endogenous ligands: focus on endocannabinoids and nociceptive signalling. Curr. Neuropharmacol. 16, 137-150. doi: $10.2174 / 1570159 X 15666170424120802$

Sun, C., Zhang, J., Chen, L., Liu, T., Xu, G., Li, C., et al. (2017). IL-17 contributed to the neuropathic pain following peripheral nerve injury by promoting astrocyte proliferation and secretion of proinflammatory cytokines. Mol. Med. Rep. 15, 89-96. doi: 10.3892/mmr.2016.6018

Sung, B., Lim, G., and Mao, J. (2003). Altered expression and uptake activity of spinal glutamate transporters after nerve injury contribute to the pathogenesis of neuropathic pain in rats. J. Neurosci. 23, 2899-2910. doi: 10.1523/jneurosci. 23-07-02899.2003

Takakuwa, K. M., and Sulak, D. (2020). A survey on the effect that medical cannabis has on prescription opioid medication usage for the treatment of chronic pain at three medical cannabis practice sites. Cureus 12:e11848. doi: 10.7759/cureus. 11848

Tsou, K., Brown, S., Sañudo-Peña, M. C., Mackie, K., and Walker, J. M. (1998). Immunohistochemical distribution of cannabinoid CB1 receptors in the rat central nervous system. Neuroscience 83, 393-411. doi: 10.1016/s0306-4522(97) 00436-3

Tsuda, M., Masuda, T., Tozaki-Saitoh, H., and Inoue, K. (2013). P2X4 receptors and neuropathic pain. Front. Cell. Neurosci. 7:191. doi: 10.3389/fncel.2013.00191

Tsuda, M., Shigemoto-Mogami, Y., Koizumi, S., Mizokoshi, A., Kohsaka, S., Salter, M. W., et al. (2003). P2X4 receptors induced in spinal microglia gate tactile allodynia after nerve injury. Nature 424, 778-783. doi: 10.1038/nature 01786

Ueberall, M. A., Essner, U., and Mueller-Schwefe, G. H. (2019). Effectiveness and tolerability of THC:CBD oromucosal spray as add-on measure in patients with severe chronic pain: analysis of 12-week open-label real-world data provided by the German Pain e-Registry. J. Pain Res. 12, 1577-1604. doi: 10.2147/jpr. S192174

van Hecke, O., Austin, S. K., Khan, R. A., Smith, B. H., and Torrance, N. (2014). Neuropathic pain in the general population: a systematic review of epidemiological studies. Pain 155, 654-662. doi: 10.1016/j.pain.2013.11.013

Veress, G., Meszar, Z., Muszil, D., Avelino, A., Matesz, K., Mackie, K., et al. (2013). Characterisation of cannabinoid 1 receptor expression in the perikarya, and 
peripheral and spinal processes of primary sensory neurons. Brain Struct. Funct. 218, 733-750. doi: 10.1007/s00429-012-0425-2

West, S. J., Bannister, K., Dickenson, A. H., and Bennett, D. L. (2015). Circuitry and plasticity of the dorsal horn-toward a better understanding of neuropathic pain. Neuroscience 300, 254-275. doi: 10.1016/j.neuroscience.2015.05.020

Wieseler-Frank, J., Maier, S. F., and Watkins, L. R. (2005). Central proinflammatory cytokines and pain enhancement. Neurosignals 14, 166-174. doi: 10.1159/ 000087655

Williams, J., Haller, V. L., Stevens, D. L., and Welch, S. P. (2008). Decreased basal endogenous opioid levels in diabetic rodents: effects on morphine and delta-9tetrahydrocannabinoid-induced antinociception. Eur. J. Pharmacol. 584, 78-86. doi: 10.1016/j.ejphar.2007.12.035

WHO (2021). Opioid Overdose. Available online at: https://www.who.int/newsroom/fact-sheets/detail/opioid-overdose (accessed October 30, 2021).

Xiong, W., Cui, T., Cheng, K., Yang, F., Chen, S. R., Willenbring, D., et al. (2012). Cannabinoids suppress inflammatory and neuropathic pain by targeting a3 glycine receptors. J. Exp. Med. 209, 1121-1134. doi: 10.1084/jem.201 20242

Yamamoto, W., Mikami, T., and Iwamura, H. (2008). Involvement of central cannabinoid CB2 receptor in reducing mechanical allodynia in a mouse model of neuropathic pain. Eur. J Pharmacol. 583, 56-61. doi: 10.1016/j.ejphar.2008. 01.010

Yang, F., Xu, Q., Shu, B., Tiwari, V., He, S. Q., Vera-Portocarrero, L. P., et al. (2016). Activation of cannabinoid $\mathrm{CB} 1$ receptor contributes to suppression of spinal nociceptive transmission and inhibition of mechanical hypersensitivity by $\mathrm{A} \beta$ fiber stimulation. Pain 157, 2582-2593. doi: 10.1097/j.pain.0000000000000680

Yekkirala, A. S., Roberson, D. P., Bean, B. P., and Woolf, C. J. (2017). Breaking barriers to novel analgesic drug development. Nat. Rev. Drug Discov. 16, 545-564. doi: 10.1038/nrd.2017.87

Zhang, G., Chen, W., Lao, L., and Marvizón, J. C. (2010). Cannabinoid CB1 receptor facilitation of substance $\mathrm{P}$ release in the rat spinal cord, measured as neurokinin 1 receptor internalization. Eur. J. Neurosci. 31, 225-237. doi: 10.1111/j.1460-9568.2009.07075.x

Zhang, J., Hoffert, C., Vu, H. K., Groblewski, T., Ahmad, S., and O’Donnell, D. (2003). Induction of CB2 receptor expression in the rat spinal cord of neuropathic but not inflammatory chronic pain models. Eur. J. Neurosci. 17, 2750-2754. doi: 10.1046/j.1460-9568.2003.02704.x

Zou, S., and Kumar, U. (2018). Cannabinoid receptors and the endocannabinoid system: signaling and function in the central nervous system. Int. J. Mol. Sci. 19:833. doi: 10.3390/ijms19030833

Zygmunt, P. M., Petersson, J., Andersson, D. A., Chuang, H., Sørgård, M., Di Marzo, V., et al. (1999). Vanilloid receptors on sensory nerves mediate the vasodilator action of anandamide. Nature 400, 452-457. doi: 10.1038/2 2761

Conflict of Interest: The authors declare that the research was conducted in the absence of any commercial or financial relationships that could be construed as a potential conflict of interest.

Publisher's Note: All claims expressed in this article are solely those of the authors and do not necessarily represent those of their affiliated organizations, or those of the publisher, the editors and the reviewers. Any product that may be evaluated in this article, or claim that may be made by its manufacturer, is not guaranteed or endorsed by the publisher.

Copyright (c) 2021 Campos, Aguiar, Paes-Colli, Trindade, Ferreira, de Melo Reis and Sampaio. This is an open-access article distributed under the terms of the Creative Commons Attribution License (CC BY). The use, distribution or reproduction in other forums is permitted, provided the original author(s) and the copyright owner(s) are credited and that the original publication in this journal is cited, in accordance with accepted academic practice. No use, distribution or reproduction is permitted which does not comply with these terms. 